Linguagem em (Dis)curso, Palhoça, SC, v. 9, n. 2, p. 303-320, maio/ago. 2009

\title{
O PROCESSO DE ESCOLHA DO LIVRO DIDÁTICO DE LÍNGUA PORTUGUESA*
}

\author{
Dulce Cassol Tagliani**
}

\begin{abstract}
Resumo: O propósito deste trabalho é analisar o processo de escolha do livro didático de Língua Portuguesa em escolas públicas de ensino fundamental, da cidade de Rio Grande, RS. Com base no Programa Nacional do Livro Didático, as escolas recebem um guia, com a avaliação das obras inscritas no programa, para orientar a escolha do material didático que será usado por um período de três anos. A partir dos dados coletados diretamente nas escolas, percebemos que o guia, mesmo com informações pertinentes e com avaliações pormenorizadas das obras, raramente é utilizado. A escolha é feita com base em análise superficial dos livros, às vezes recaindo em obras com problemas já apontados pelo guia.

Palavras-chave: ensino; Língua Portuguesa; livro didático.
\end{abstract}

\section{INTRODUÇÃO}

O processo de ensino-aprendizagem de língua portuguesa é objeto de discussão em diferentes níveis. Inúmeros estudiosos, de diferentes filiações teóricas, procuram trazer à tona os principais problemas que envolvem tal processo. Com relação ao livro didático de língua portuguesa não é diferente. A discussão se volta, principalmente, para o uso, ou não, do material que hoje é disponibilizado pelo governo federal

\footnotetext{
* Este trabalho faz parte de uma pesquisa de doutorado, intitulada "O Livro Didático de Língua Portuguesa no contexto escolar: perspectivas de interação", defendida no Programa de PósGraduação em Letras da Universidade Católica de Pelotas em 2009.

** Professora da Universidade Federal do Rio Grande (FURG), Rio Grande, RS, Brasil. Doutora em Letras/Linguística Aplicada. Email: <dulcetagliani@vetorial.ne>
} 
às escolas públicas do país, níveis fundamental e médio, e, também, para a qualidade desse material.

O surgimento do livro didático (LD), conforme Bezerra (2003), deve-se às transformações que o ensino de Língua Portuguesa sofreu. Inicialmente, tínhamos um ensino voltado apenas para as classes com elevado nível de letramento - professores e alunos de classes privilegiadas. Posteriormente, o ensino foi democratizado, porém os conhecimentos gramaticais dos envolvidos eram precários. Dessa forma, os manuais didáticos, que já existiam na forma de antologias, recebem nova "roupagem", com o objetivo de suprir as deficiências dos professores. Atualmente, o uso de livros didáticos é bastante comum nas escolas e, em muitos casos, facilita sobremaneira a vida do professor, servindo de "tábua de salvação" para professores despreparados e/ou com sobrecarga de trabalho e assumindo o papel de sujeito no processo de ensino-aprendizagem (FREGONEZI, 2003). Entretanto, conforme informações contidas no Guia do Livro Didático (BRASIL, 2007, p.19), o trabalho com o material "não pode prescindir do professor", que deve "pensar nos usos diferenciados que um LD pode permitir, como alterações de sequências, atividades complementares, aspectos diversos da realidade local etc".

A oposição que, de certa maneira, ainda se mantém ao livro didático vem desde a década de 70 e, principalmente, a de 80 , quando o material didático era visto "como uma tecnologia pouco adequada a processos efetivos de aprendizado; como resultado de interesses econômicos envolvidos em sua produção e comercialização; e identificado aos efeitos de controle que exerce sobre a ação docente e sobre o currículo" (ROJO; BATISTA, 2003, p. 45). A concepção de livro didático que se tinha, então, é de estruturador das práticas docentes em função da intensa ampliação do sistema de ensino e de processos de recrutamento docente mais amplos e menos seletivos.

Segundo Rojo e Batista (2003, p. 49), essa concepção ainda persiste e é pouco adequada para responder às exigências apresentadas pelo contexto educacional contemporâneo, "marcado pela afirmação da diversidade e flexibilidade das formas de organização escolar, originadas pela necessidade de atender aos diferentes interesses e expectativas gerados por fatores de ordem cultural, social e regional". Assim, é necessário, segundo os autores, que se amplie essa concepção de livro

TAGLIANI - O processo de escolha do livro didático... 
didático, também pressuposta pelo Programa Nacional do Livro Didático (PNLD), para que tenhamos um ensino de melhor qualidade e adequado às exigências atuais.

Um aspecto importante a ser considerado, e que também é objetivo deste trabalho, é em relação aos critérios que envolvem a escolha do material didático. Sendo assim, procuramos verificar em que medida os professores de língua portuguesa se valem de critérios, sejam eles disponibilizados pelo Guia do Livro Didático, ou critérios estabelecidos pela área de língua portuguesa das escolas, ou, ainda, critérios próprios de cada professor na escolha do material a ser utilizado. Nosso principal objetivo, portanto, é discutir o processo de escolha do livro didático de língua portuguesa.

Nesse sentido, trabalhamos com quatro professores do ensino fundamental de quatro escolas públicas do município de Rio Grande/RS. A escolha das escolas foi baseada na disponibilidade dos professores em participar da pesquisa. As entrevistas com os professores foram feitas com base em questões norteadoras (anexo 1) organizadas para este fim.

Com base nos aspectos apresentados acima, o texto se desenvolve a partir de um breve panorama sobre a questão do LD no Brasil, as ações do PNLD, que culminam no Guia do Livro Didático, e os primeiros resultados da pesquisa.

\section{O QUE É O PROGRAMA NACIONAL DO LIVRO DIDÁTICO (PNLD)}

O PNLD é uma iniciativa do MEC com o objetivo de adquirir e distribuir gratuitamente livros didáticos às escolas públicas do país. Esse programa foi criado em 1985, mas somente a partir de 1996 passa a desenvolver um processo de avaliação pedagógica das obras nele inscritas, resultado da preocupação do MEC com a qualidade dessas obras. Assim, o material didático passa por um processo de análise e avaliação, considerando-se, principalmente, a adequação didática e pedagógica, a qualidade editorial e gráfica e a pertinência do manual do professor para uma correta utilização do LD e atualização do docente. 
Como critérios eliminatórios, observam-se o caráter ideológico e discriminatório, desatualização, incorreções e incoerências conceituais e metodológicas. Com base nesses critérios, o PNLD indica as obras recomendadas, disponibilizadas ao professor por meio do Guia do Livro Didático, que apresenta as resenhas e as avaliações relacionadas a esses livros.

O PNLD tem passado por inúmeras modificações desde sua implantação, em função dos diferentes paradigmas educacionais, das orientações dadas pelas Diretrizes Curriculares Nacionais, pelos Parâmetros Curriculares Nacionais e pela LDB, o que evidencia, segundo Rojo e Batista (2003), a busca constante para solucionar problemas e dar uma resposta adequada à complexa realidade do $\mathrm{LD}$ nos contextos editorial e educacional brasileiros. Desse modo, a avaliação feita pela equipe do PNLD objetiva uma ampla renovação da produção de material didático, o que faz com que as editoras inscritas no programa tenham a preocupação constante de adequação dos livros didáticos às exigências estabelecidas.

[...] com livros de melhor qualidade nas escolas, o PNLD vem contribuindo para um ensino de melhor qualidade: é uma referência consensual de qualidade para a produção de livros didáticos e para sua escolha, por professores; vem possibilitando uma reformulação dos padrões do manual escolar brasileiro e criando condições adequadas para a renovação das práticas de ensino nas escolas. (ROJO; BATISTA, 2003, p.41)

Apesar das periódicas avaliações feitas, o LD ainda apresenta problemas, como comprovam as pesquisas, mas se constitui num instrumento bastante útil para o ensino de Língua Portuguesa. Nesse sentido, destacamos a importância de pesquisas voltadas para a discussão desse tema, principalmente se considerarmos o uso que será feito do material disponibilizado.

\section{O GUIA DO LIVRO DIDÁTICO}

Em que medida um livro pode ser um recurso determinante no processo de ensino-aprendizagem de língua portuguesa? Conforme o 
Guia do Livro Didático 2008 (GLD/2008), o "livro é o domínio por excelência da escrita [...] é por meio dele que temos acesso privilegiado à cultura letrada" (BRASIL, 2007, p. 12). Nesse sentido, acrescenta:

[...] ler e escrever são competências básicas, tanto para a conquista progressiva da autonomia nos estudos, quanto para o sucesso escolar. Talvez por simbolizar todas essas promessas, o livro assim como o caderno novo, de que nos fala João Cabral, em Morte e vida Severina - é capaz de exercer um grande fascínio sobre o aprendiz, seduzindo-o de uma forma muito própria [...]

O GLD é um manual que pretende auxiliar o professor no momento da escolha do material didático a ser utilizado nas escolas públicas do país. Nesse sentido, apresenta a seu leitor, o professor, resenhas de obras que foram avaliadas e são recomendadas pelo PNLD, seguindo concepções teóricas e princípios político-pedagógicos considerados mais adequados ao atual momento do processo de ensinoaprendizagem nas escolas brasileiras.

As resenhas que constam no guia apontam para os aspectos significativos de cada obra, visando orientar o professor quanto à escolha que deve ser feita, levando em consideração, entre outros aspectos, a proposta pedagógica da escola. A escolha, conforme informações do guia, deve seguir um processo criterioso de análise por parte do professor, visto que as obras recomendadas diferem entre si "quer no grau de adesão aos critérios de qualidade, quer na forma com que organizam suas propostas didáticas, propiciando dinâmicas de trabalho às vezes bastante diferenciadas" (BRASIL, 2007, p. 13).

O guia apresenta, ainda, em sua parte introdutória, uma série de reflexões que pretende auxiliar o professor a fazer sua escolha da forma mais consciente possível. Além disso, explicita algumas condições a que o acesso ao livro escolhido está submetido: vigência de três anos, negociação do Fundo Nacional de Desenvolvimento da Educação (FNDE) com autores e editores, a 'reserva técnica' e seus limites e o formulário a ser preenchido.

Algumas das orientações dadas já na apresentação do GLD referem-se a:

a) impossibilidade de aquisição da obra escolhida. Sendo assim, a segunda opção deve ser tão "pra valer" quanto a primeira - a 
segunda opção também é uma opção, e não deve ser aleatória. Deve envolver uma editora diferente, para evitar eventuais contratempos (p. 11);

b) escolha propriamente dita: "não se esqueçam de que, no PNLD, a escolha de uma mesma obra para uma disciplina vale para toda a escola" (p. 13). Benefícios dessa condição: o uso de um único livro é uma referência importante para a organização prática do trabalho didático-pedagógico - articulação mais estreita e mais ágil entre as equipes de diferentes turnos e séries; alunos ou professores que mudem de turno ou turma são beneficiados; fortalecimento do trabalho coletivo e do projeto pedagógico e curricular da escola;

c) o livro como um objeto; o que pode transformá-lo numa atraente "biblioteca verde" é o "uso adequado à situação de cada escola"; um LD não pode desconhecer as conquistas propiciadas pelas teorias da aprendizagem, o que tem levado à aposentadoria muitas crenças atualmente infundadas em que o ensino se baseava (p. 14);

d) avaliação do LD em uso, isto é, antes de ler o guia, é importante avaliar o livro utilizado até então (satisfatório ou não? Em que pontos?).

Ainda de acordo com o guia, do ponto de vista do professor, um bom livro deve desempenhar funções que caracterizem um trabalho pedagógico diferenciado: informação científica e geral, formação pedagógica diretamente relacionada à disciplina em questão, ajuda no desenvolvimento das aulas e ajuda na avaliação dos conhecimentos práticos e teóricos adquiridos. Considerando tais aspectos, o LD deverá estar de acordo com as conquistas na área da aprendizagem, com o projeto pedagógico da escola, ter flexibilidade para explorações diversificadas propiciadas pelo uso coletivo da obra e considerar a infraestrutura da escola e condições de trabalho disponíveis.

Com relação ao tratamento didático dado aos conteúdos básicos da disciplina, o GLD/Língua Portuguesa/2008 (BRASIL, 2007) aponta quatro tendências metodológicas recorrentes: 
a) vivência: "investe na ideia de que o aluno aprende o conteúdo vivenciando situações escolares em que esse conteúdo está diretamente envolvido" (p. 19);

b) transmissão: “a aprendizagem de um determinado conteúdo deve se dar como assimilação, pelo aluno, de informações, noções e conceitos, organizados logicamente pelo professor e/ou pelos materiais didáticos" (p. 19);

c) uso situado: "o ensino parte de um uso socialmente contextualizado do conteúdo" (p.19);

d) construção/reflexão: “o tratamento didático do conteúdo leva o aprendiz a, num primeiro momento, refletir sobre certos dados ou fatos, para posteriormente inferir, com base em análise devidamente orientada, o conhecimento em questão" (p. 20).

O GLD/LP/2008 oferece, ainda, ao professor um quadro-síntese das coleções analisadas, objetivando colaborar na organização do processo de escolha. Tal quadro oferece o perfil metodológico das obras, combinando o princípio organizador da matéria ao tipo de abordagem dada aos quatro conteúdos curriculares básicos: leitura, produção de textos escritos, oralidade e conhecimentos linguísticos.

No anexo 2, encontramos as obras escolhidas pelos professores participantes da pesquisa para serem usadas no ano letivo de 2008, com a síntese de cada uma delas, apresentada pelo GLD/LP/2008.

\section{OS PRIMEIROS RESULTADOS}

Este trabalho, como dito anteriormente, foi realizado com quatro professores que atuam no ensino fundamental de escolas públicas de Rio Grande/RS. A pesquisa iniciada em 2007, com a investigação sobre o processo de escolha do LD, teve continuidade no decorrer do ano letivo de 2008 com observações de aulas desses professores. Tais observações foram feitas com o objetivo de verificar o uso que é feito do LD escolhido pelas escolas. É interessante salientar que a direção das escolas mostrou-se totalmente favorável à proposta apresentada, em função da 
colaboração efetiva que pesquisas deste tipo podem dar ao processo de ensino-aprendizagem.

Com base, então, nos questionamentos realizados (anexo 1) durante a conversa com os professores, destacamos os seguintes aspectos:

a) com relação ao primeiro quesito pesquisado - como foi o processo de escolha do LD de português? -, observamos que em apenas uma das escolas os professores analisaram o Guia do LD disponibilizado pelo MEC. Nas outras três escolas houve dois procedimentos distintos: (i) os professores levaram exemplares de alguns livros para casa e tiveram cerca de uma semana para analisá-los e escolher qual seria mais apropriado; depois disso, a escola disponibilizou tempo aos professores para uma reunião, na qual o material foi discutido e escolhido; (ii) os professores procederam à análise de alguns exemplares enviados pelas editoras, na própria escola - a escolha, então, foi feita posteriormente, em uma reunião com o grupo de professores;

b) agrupando os aspectos destacados pelos professores com relação aos questionamentos dois, três e quatro - lista de obras, disponibilização do primeiro indicado e definição de chegada dos livros à escola -, os resultados demonstram que foram feitas listas de dois a três livros, em ordem de preferência, mas os professores destacaram que nem sempre recebem os livros escolhidos. Algumas escolas já receberam o material; em outras escolas, os livros chegariam até o final do ano de 2007. Uma única escola desconhecia, no momento da pesquisa, a obra que seria enviada pelo governo;

c) no item seguinte, que procurou verificar se a escolha do material foi consensual, em todas as escolas os professores da área concordaram com a indicação do LD;

d) considerando os aspectos que mais influenciaram na escolha do material didático, os resultados indicam que os pontos mais enfatizados pelos professores são: textos e atividades de interpretação; exercícios apresentados; textos, atividades gramaticais e de produção de textos; apresentação que 
chame a atenção do aluno, textos atrativos e exercícios contextualizados; nem extremamente gramatical nem linguístico, que abordem conteúdos gramaticais, linguísticos, interpretação e produção textual;

e) com relação à discussão dos aspectos teóricos que embasam a obra, se foram ou não determinantes na escolha, há duas possibilidades: ou os aspectos teóricos foram discutidos e considerados; ou eles foram desconsiderados no processo de escolha (este procedimento predominou);

f) na questão relacionada aos autores das obras, verificamos que livros de autores já conhecidos pelos professores foram deixados de lado, em função de considerarem que a obra usada até então não contemplava os aspectos de que necessitavam;

g) por fim, os professores destacam que as escolas disponibilizaram tempo para reuniões voltadas para a escolha do LD (apesar de poucas reuniões), mas não houve consulta ao setor pedagógico na maioria delas; entretanto, em uma dessas escolas, o setor pedagógico foi consultado para questões envolvendo a apresentação e a metodologia do material.

Além desses aspectos, os professores fizeram algumas colocações que merecem atenção. Entre elas, destacaram como dificuldade a necessidade de escolha de um "pacote completo", isto é, a escola deve escolher uma coleção completa para todas as séries do ensino fundamental, mesmo que considerem inadequadas algumas obras para algumas das séries.

Outro aspecto negativo apresentado pelos professores relacionase à influência das editoras no processo de escolha do LD. Segundo eles, algumas editoras oferecem benefícios à escola caso seus livros sejam escolhidos. Com isso, certas pressões acabam surgindo por parte da direção, em função, muitas vezes, da carência de material permanente das escolas públicas.

Ainda com relação aos problemas enfrentados durante esse processo de escolha, os professores destacam que, na maioria dos casos, o programa a ser desenvolvido em cada série não coincide com o conteúdo disponibilizado pelo LD. Sendo assim, os livros serão 
subutilizados, destinados a atividades de leitura e produção de textos. Por fim, foi destacada a questão da falta de interação entre os professores da mesma disciplina dentro do ambiente escolar, o que dificulta a tomada de decisões em grupo.

\section{DISCUSSÃO DOS RESULTADOS}

Antes de iniciarmos a discussão dos aspectos observados na pesquisa, é necessário esclarecermos que o GLD está sendo aqui considerado apenas como um manual e/ou instrumento de que dispõem os professores da rede pública de ensino para a escolha dos LD a serem utilizados em suas respectivas escolas. Não vamos discutir, neste momento, o discurso oficial que perpassa essa publicação. O GLD disponibilizado pelo MEC é, obviamente, "produzido por um sujeito histórico, que detém autoridade e representa o poder no seu papel sóciopolítico" (BORGES, 2003, p. 3). Vamos apenas considerar, em consonância com Rangel (2005, p. 18), que o conjunto de critérios pelo qual se pauta a avaliação dos LD "pretende garantir [...] que o LD disponível para a escola pública contribua efetivamente para a consecução dos objetivos do ensino de língua materna no ensino fundamental", e que o guia pode auxiliar na escolha mais adequada a cada contexto escolar.

Retomando os aspectos levantados junto aos professores participantes desta pesquisa, podemos dizer que, para eles, o GLD não foi fundamental para a escolha do LD a ser utilizado no triênio 20082010. Com exceção de uma das quatro escolas observadas, as demais não fizeram qualquer referência ao guia. É como se ele nem tivesse chegado a essas escolas. Ao que parece, a escolha do professor é feita de forma individual, sem discussões que ampliem a visão que ele possa vir a ter da obra a ser escolhida. Nesse sentido, observamos que todo o longo processo de análise e avaliação dos livros inscritos no PNLD, e que culmina com o guia, se esvazia, não é considerado no momento da escolha do material didático. Esse processo de escolha do LD poderia ser uma oportunidade de estar em contato com as transformações pelas quais vem passando o processo de ensino-aprendizagem de língua 
materna, que, conforme o guia, se refletem em boa parte do material didático recomendado. Tais transformações estão relacionadas, conforme Rangel (2005, p. 14), à “'virada pragmática' no ensino de língua materna, caracterizada por uma brusca mudança na concepção do que seja ensinar língua materna", concepção esta que tem no uso da linguagem o objeto de reflexão.

Conforme observamos nas entrevistas feitas com os professores, parece não haver um envolvimento efetivo da área de LP e setor pedagógico da escola para uma escolha consciente. Critérios não foram estabelecidos, nem mesmo os sugeridos pelo guia, o que torna a tarefa de escolha do LD um tanto superficial, pois se reduz à observação da presença de textos interessantes, atividades de interpretação e produção de textos, além dos tópicos gramaticais. Algumas questões importantes são desconsideradas, como a organização didática e metodológica das práticas de uso da linguagem e das práticas de reflexão sobre a língua, no sentido de considerar o "ensino de estratégias de abordagem, compreensão e construção do texto, essenciais para a eficácia do discurso" (RANGEL, 2005, 16). Tais questões são discutidas no guia, que apresenta uma avaliação de cada um desses aspectos de acordo com a abordagem metodológica pretendida.

Ao considerarmos as resenhas das três obras escolhidas pelos professores, podemos ampliar a afirmação anterior. Por exemplo, com relação às obras 143 e 093, cujas resenhas estão no anexo 2, observamos que a abordagem metodológica é heterogênea nos aspectos que envolvem leitura, produção de textos escritos e oralidade, porém, especificamente no aspecto "conhecimento linguístico" (altamente priorizado nas aulas de língua portuguesa), o tratamento didático dispensado é o transmissivo, o que significa que o ensino de gramática continua se valendo da definição de conceitos e regras, seguida de exemplos e atividades de aplicação.

Com a obra 141 não é muito diferente. Apesar de constar no guia uma leve tentativa de trabalhar os conteúdos gramaticais de maneira diferente (abordagem metodológica que considera a construção/reflexão), o que predomina também é a transmissão.

Nesse sentido, podemos considerar que a escolha do material não é feita de forma a contemplar os aspectos básicos do ensino de língua 
materna e a relação que se estabelece entre eles. Nesse sentido, Rangel (2005, p. 17) explicita que

[...] a metalinguagem deverá, sim, ser explicitada e sistematizada, mas paulatinamente, ao sabor das necessidades e demandas do ensino das práticas de leitura, produção e oralidade. E então poderá funcionar como uma espécie de teoria auxiliar, como um conhecimento conceitual a que se pode recorrer para monitorar e aprimorar a prática, assim como para entender a natureza e o funcionamento da linguagem.

As orientações do guia indicam se as obras dão mais ênfase a um ou outro aspecto, se a organização didática dos conteúdos reflete uma preocupação dos autores com um processo de ensino-aprendizagem adequado às necessidades atuais do aluno, o qual está inserido em diferentes contextos econômicos, culturais e sociais.

Por outro lado, devemos considerar, neste processo, se as resenhas das obras foram produzidas com grau de informatividade e nível enunciativo que propiciem ao professor fazer delas uma leitura crítica, ou, ainda, se o guia, como um todo, corresponde à formação do professor. Talvez o que esteja ocorrendo seja um descompasso entre o pensamento teórico apresentado pelo guia e o pensamento prático do professor. Nesse sentido, temos apenas uma pressuposição de que o professor irá interagir com as teorias subjacentes aos documentos oficiais.

Com relação ao processo de escolha observado, percebemos que os aspectos teóricos que embasam as obras foram desconsiderados pela maioria dos professores. Como explicitam algumas pesquisas, entre elas a de Ticks (2003, p. 39), o professor parece não ter condições de analisar "os conceitos subjacentes de linguagem, ensino e aprendizagem e em que medida esses mesmos conceitos se afinam com aqueles dos próprios professores que desejam adotá-los". Esta e outras causas, como formação deficiente - inicial ou continuada, desconhecimento das conquistas propiciadas pelas teorias da aprendizagem, precariedade das escolas públicas e as péssimas condições de trabalho do professor podem ter contribuído para que o processo de escolha não tenha sido o mais adequado. Além disso, não há diálogo efetivo entre teóricos e professores de ensino fundamental e médio, o que pode estar 
dificultando a interação entre a teoria (de fundamental importância) e a prática (tão importante quanto). Tal distanciamento é bastante amplo e, ao que tudo indica, está longe de ser reduzido.

Ainda com relação às entrevistas, os professores disseram que os autores das obras não foram considerados na hora da escolha, apenas em uma escola eles resolveram não escolher o autor do LD do ano anterior por considerarem que a obra usada até então não estava satisfazendo suas necessidades pedagógicas. Este é um aspecto importante mencionado pelo GLD, que destaca como fundamental a avaliação do livro em uso - se é satisfatório ou não e em que pontos - para que a próxima escolha possa ser mais adequada e consciente.

\section{CONSIDERAÇÕES FINAIS}

Percebemos, com base nos aspectos discutidos, que a escolha do material didático pelo professor de língua portuguesa envolve bem mais do que uma ou duas reuniões para discussão; é um percurso bastante longo a ser percorrido - o próprio guia dá orientações nesse sentido, o que, talvez, não se encaixe no ritmo de trabalho da maioria dos professores da rede pública, que acumulam horas de trabalho em dois e até três turnos diários.

No entanto, não podemos prescindir de um ensino de língua materna vinculado a formas específicas de (inter)agir, o que vai de encontro ao que ainda tem acontecido em muitas salas de aula de língua portuguesa, ou seja, a transmissão de um conjunto de informações sobre a língua. É importante considerar que a formação de um indivíduo passa, também, pelo desenvolvimento de competências e habilidades que envolvem o domínio crescente de recursos e "procedimentos de construção e reconstrução das tramas linguísticas capazes de, nas situações para as quais foram traçadas, produzir os sentidos pretendidos pelos sujeitos" (RANGEL, 2005, p. 17).

Nesse sentido, o GLD é produto de uma avaliação que pretende justamente atender a essa demanda, ou seja, pretende que o LD priorize aspectos que reflitam uma nova visão de ensino de língua materna, aspectos que, conforme Rangel (2005), envolvem o discurso, os padrões 
de letramento, a língua oral, a textualidade, as diferentes gramáticas de uma mesma língua etc. Para isso, a escolha do material didático parece fundamental, apesar do descompasso verificado entre as pressuposições do guia e o que é feito pelo professor. Tal descompasso pode estar associado, principalmente, às condições de trabalho da maioria dos professores das escolas públicas brasileiras, em função de uma política governamental que não prioriza a formação e valorização da carreira docente. Percebemos, então, uma contradição entre o que se espera de um processo de escolha de um LD (apresentado pelo guia) e o que se oferece para que o processo tenha validade.

Com base nas considerações feitas, percebemos que a discussão em torno do papel do livro didático no processo de ensinoaprendizagem não deve se esgotar na popular expressão "ame-o ou deixe-o". As discussões em torno do uso do material didático devem se ampliar e se aprofundar, no sentido de envolver cada vez mais pessoas interessadas em refletir sobre um ensino que pode ser considerado como um novo paradigma, envolvendo práticas de ensino que privilegiam o aprendiz e o consideram sujeito ativo no processo, além de considerar as diversas situações e contextos que envolvem essas práticas.

\section{REFERÊNCIAS}

BEZERRA, M. A. Ensino de língua portuguesa e contextos teóricometodológicos. In: DIONISIO, A.; MACHADO, A.; BEZERRA, M. A. (Orgs.). Gêneros textuais e ensino. 2. ed. Rio de Janeiro: Lucerna, 2003.

BORGES, C. O Guia dos livros didáticos: como se comporta o professor? Partes: revista virtual, n. 34, jun. 2003. Disponível em: < http://www.partes. com.br/ed34/emquestao.asp>. Acesso em: 29 jan. 2008.

BRASIL. Ministério da Educação. Guia de livros didáticos PNLD 2008: apresentação. Brasília: MEC, 2007.

. Ministério da Educação. Guia de livros didáticos PNLD 2008:

Língua Portuguesa. Brasília: MEC, 2007.

TAGLIANI - O processo de escolha do livro didático... 
FREGONEZI, D. Livro didático de Língua Portuguesa: liberdade ou opressão? In: LEFFA, V. (Org.). Tela 2 (Textos em Linguística Aplicada). CD-rom. Pelotas: Educat, 2003.

RANGEL, E. Livro didático de língua portuguesa: o retorno do recalcado. In: DIONISIO, A.; BEZERRA. M. A. O livro didático de português: múltiplos olhares. Rio de Janeiro: Lucerna, 2005.

ROJO, R.; BATISTA, A. Livro didático de língua portuguesa, letramento e cultura da escrita. Campinas, SP: Mercado de Letras, 2003.

TICKS, L. K. Contribuições da análise de gênero para o estudo de conceitos de linguagem em livros didáticos e no discurso de professores de inglês. 2003. 142 f. Dissertação (Mestrado em Letras) - Programa de PósGraduação em Letras, Universidade Federal de Santa Maria, Santa Maria, RS, 2003.

\section{ANEXO 1}

\section{Questões norteadoras para as entrevistas}

1. Como foi o processo de escolha do LD de português? (por ex: reuniões para discussão, análise individual/escolha do mais "votado")

2. Foi feita uma lista com as obras preferidas e em ordem de preferência? Quantos títulos compõem a lista? Quais são?

3. Já há uma definição sobre o livro que será usado? (área de português/ensino fundamental)? Quando os livros chegam à escola? (ou já chegaram?)

4. O LD que será disponibilizado foi o primeiro da lista?

5. A escolha foi consensual?

6. Quais os aspectos que influenciaram sua escolha? (textos, embasamento teórico, atividades gramaticais e/ou de leitura e/ou de produção de textos)

7. Os aspectos teóricos que embasam a obra foram discutidos/foram determinantes na escolha?

8. Já conhecia o(s) autor(es) do livro escolhido? (por ter trabalhado com material por ele(s) organizado) 
9. Houve tempo para discutir a escolha do LD? (tempo disponibilizado pela escola)

10. Durante a escolha, houve discussão e/ou consulta ao setor pedagógico da escola?

\section{ANEXO 2}

\section{As obras escolhidas}

* 143 - Português: ideias e linguagens, de Dileta Delmanto e Maria da Conceição Castro

Síntese: Os principais destaques desta coleção são as abundantes, variadas e bem articuladas propostas de produção, tanto oral quanto escrita. Também chamam a atenção os projetos propostos em algumas unidades, que possibilitam ao professor gerar situações de leitura e produção escrita instigantes e criativas para os alunos. As atividades de leitura são detalhadas e trabalham diversas habilidades, mas não se voltam para a formação do leitor literário. A seção dedicada aos estudos gramaticais apresenta os conceitos de forma clara, a partir da observação de fatos do sistema linguístico, e privilegia a identificação e classificação de formas e estruturas. Esse trabalho, no entanto, é muito extenso e descontextualizado (p. 127).

* 141 - Português Linguagens, de William Cereja e Thereza Magalhães Síntese: A coleção elege os gêneros como objetos de ensino e os vincula à realização de projetos temáticos. Nessa perspectiva, desenvolve uma proposta de ensino construtivo em leitura, produção escrita e análise linguística, possibilitando aos alunos apropriarem-se das características temáticas, estruturais e estilísticas dos gêneros em estudo. No tratamento da gramática, a obra adota a abordagem tradicional dos conteúdos, voltada para a exposição de conceitos e classificações e a prescrição de normas de uso. O trabalho com a oralidade contempla a produção de alguns gêneros adequados para situações públicas e formais, cujas características são abordadas de forma transmissiva (p. 145). 
* 093 - Português para todos, de Ernani Terra e Floriana Cavallete

Síntese: Destacam-se na coleção a diversidade da coletânea e as propostas de produção escrita, articuladas aos temas de leitura. Sugestões de pesquisas e elaboração de projetos alimentam a produção oral e a escrita. As atividades de leitura trazem dados sobre o autor e exploram a compreensão do texto e sua estrutura; entretanto dão pouca atenção aos aspectos discursivos (ex.: intertextualidade, relação entre recursos expressivos e efeitos de sentidos). A abordagem dos conhecimentos linguísticos é predominantemente transmissiva e centrada em conteúdos gramaticais. Há oportunidades de uso da língua falada em aula, mas são pouco focalizados os gêneros orais e a relação fala/escrita (p.81).

\section{Recebido em 29/04/08. Aprovado em 09/06/09.}

Title: The selection of Portuguese textbooks

Author: Dulce Cassol Tagliani

Abstract: This paper deals with issues related to the selection of Portuguese textbooks in primary public schools in Rio Grande, Southern Brazil. According to the National Textbook Program, the schools receive a manual with an evaluation of the textbooks submitted to the Program, which provides some guidance on how to choose a textbook to be used at school. This study investigates how the Portuguese teachers choose the textbook they want to use. The schools were visited and the teachers were interviewed. The data collected reveal that the Textbook Guide is rarely used. The selection is usually made based on a superficial analysis of the books, and sometimes the choice falls on textbooks evaluated by the the official guide as having problems.

Keywords: teaching; Portuguese language; textbook.

Titre: Le procès dans le choix du livre didactique de Langue Portugaise

Auteur: Dulce Cassol Tagliani

Résumé: La proposition de ce travail est celle d'analyser le procès dans le choix du livre didactique de Langue Portugaise dans les écoles publiques d'enseignement fondamental, de la ville de Rio Grande, dans l'état de Rio Grande do Sul. Fondées dans le Programme National du Livre Didactique, les écoles reçoivent un guide, avec l'évaluation des œuvres inscrites dans le programme, pour orienter le choix du matériel didactique qui va être employé pendant une période de trois ans. À partir des données ramassées directement dans les écoles, on se rend compte que le guide, même présentant des informations pertinentes et avec des évaluations examinées en détail de ces œuvres, est employé rarement. Le choix est fait ayant comme base une analyse superficielle des livres, parfois retombant dans des œuvres qui ont des problèmes déjà indiqués par le guide. 
Mots-clés: enseignement; Langue Portugaise; livre didactique.

Título: El proceso de elección del libro didáctico de Lengua Portuguesa

Autor: Dulce Cassol Tagliani

Resumen: El propósito de este trabajo e analizar el proceso de elección del libro didáctico de Lengua Portuguesa en escuelas públicas de enseñanza fundamental, de la ciudad de Rio Grande, RS. Con base en el Programa Nacional del Libro Didáctico, las escuelas reciben una guía, con la evaluación de las obras inscriptas en el programa, para orientar la elección del material didáctico que será usado por un período de tres años. A partir de los datos colectados directamente en las escuelas, percibimos que la guía, aunque con informaciones pertinentes y con evaluaciones pormenorizadas de las obras, raramente es utilizada. La elección es hecha con base en análisis superficial de los libros, a veces recayendo en obras con problemas ya apuntados por la guia.

Palabras-clave: enseñanza; Lengua Portuguesa; libro didáctico. 